\title{
Neural tube malformations: complex segregation analysis and calculation of recurrence risks ${ }^{1}$
}

\author{
J. M. LALOUEL, N. E. MORTON, AND J. JACKSON
}

From the Population Genetics Laboratory, University of Hawaii, Honolulu, Hawaii; and the Department of Preventive Medicine, School of Medicine, University of Mississippi Medical Center, Jackson, Mississippi 39216, USA

SUMMARY Familial data on neural tube malformations in Great Britain were submitted to segre:-1 gation analysis under the mixed model. Maternal and fetal factors cannot be discriminated in the absence of substantial bodies of data on spina bifida survivors who reproduce or on half-sibs. Earlyo abortion studies would allow differential mortality in utero to be taken into account. After fitting the mixed and generalised single locus models, it is concluded that the multifactorial model can provisionally be used for calculation of recurrence risks. Pathogenic hypotheses implicating twinning seem to rest on little evidence.

Epidemiological features and the pattern of familial aggregation of neural tube malformations suggest genetic as well as environmental factors at play in their causation.

Two large bodies of data from Britain are submitted to segregation analysis under the mixed model (Morton and MacLean, 1974), and the best fitting model is used for calculation of specific recurrence risks.

\section{Neural tube malformations}

This term covers a variety of congenital malformations-anencephaly, iniencephaly, encephalocele, myelocele, and meningocele (but not hydrocephalus) - sharing a number of epidemiological features which, together with their co-occurrence in families (Carter et al., 1968; Smith, 1976), suggest that they have a common aetiology. In family studies, it is usual to include encephalocele, meningocele, and myelocele with spina bifida cystica, and iniencephaly with anencephaly.

\section{EPIDEMIOLOGICAL FEAT URES}

The frequency of neural tube malformations among all births, live and stillbirths, has been found to vary with time, space, ethnic group, socioeconomic status, sex, maternal age, and parity. This frequency varies by a factor of three in various community

${ }^{1}$ This work was supported by grants GM 23498 and GM 17173 from US National Institutes of Health.

Received for publication 5 July 1978 surveys in the United Kingdom: 0.0030, 0.005\% 0.0076 , and 0.0087 , respectively, in four representative surveys in Greater London (Carter and Evans? 1973a), Glasgow (Wilson, 1970), South Wales (Carter et al., 1968), and Belfast (Elwood and Nevir 1973). This gradient is corroborated by a number of other reliable surveys and the ratio of the frequencies of spina bifida and anencephaly is sensibly constan $\vec{E}$ with, in general, a slight excess of spina bifida (J. H. Elwood, 1976).

Caution should be exercised in internation comparisons because of variation in the method of ascertainment, as discussed in the present contex by Naggan (1976). Frequencies greater than 0.009 are seldom reported outside the British Isles (Leck. 1972), and there is good reason to suspect that i⿱⺈ some of these instances estimates are biased up wards by surveying of highly specialised referra centres (Naggan, 1976). When classified by majos ethnic groups, reported frequencies are striking low in Mongoloids and Negroids, and highlys variable among Caucasoids. The comparative studies of descendants of migrants have not resolved the question of whether this variability is primarifo geographical or ethnic. The frequency of neural tube malformations seems to vary following migration for most Caucasoids, towards that of the autocts thon population (Morton et al., 1967; Naggan anf MacMahon, 1967; Leck, 1969; Naggan, 1976), bud this is not observed for Ashkenazi Jews in Bosto (Naggan and MacMahon, 1967), or for Negro populations (Leck, 1969, 1972). This pattern may 
affected by other uncontrolled sources of variation, such as ascertainment, socioeconomic status, or demographic composition, or it may be real. However, a differential response to a change of environment depends on differences in genetic liability as well as on variable rates of acculturation, so that this issue has not been settled. Another interesting feature in connection with geographical variation is that relative frequencies of anencephaly and spina bifida are generally of the same order, except in Oriental populations where spina bifida is relatively less frequent (Neel, 1958; Imaizumi, 1974; Leck, 1974).

Secular variations, as well as seasonal fluctuations, have been observed in many North American or British studies (for a review, see J. H. Elwood, 1976; J. M. Elwood, 1976), possibly incriminating the influence of as yet unidentified environmental factors. An association with socioeconomic status, with greater frequency of malformations in poorer socioeconomic groups, has been found in most British studies (J. H. Elwood, 1976).

The frequency of neural tube malformations among all births, live or stillbirths, has been found to be higher among females than males in most large series reported (Timson, 1969, 1970), and more strikingly so for anencephaly alone, with a sex ratio below 0.45:1 in the British Isles. However, sex ratios around unity have been reported for Oriental populations (Neel, 1958; Searle, 1959; Imaizumi, 1974), suggesting that high ratios may be characteristic of populations with low frequency of these malformations (Naggan, 1971).

Associations with maternal age and parity have been found in various studies, but the patterns reported vary between countries. The most widely observed maternal age effect is one of positive association, and for parity the only finding common to these studies is that frequency is low in second births (Leck, 1974). But whereas the rate in first births is low in Israel (Naggan, 1976), it is higher than at any subsequent birth rank in the British Isles. The typical pattern found in the British Isles is that the older the primipara, the lower the frequency of neural tube malformations, but the older the multipara, the higher this frequency is, and little of this pattern can be ascribed to the social class effect (Fedrick, 1970).

\section{FAMILY STUDIES}

In a number of recent family studies (Williamson, 1965; Carter et al., 1968; Yen and MacMahon, 1968; Richards et al., 1972; Carter and Evans, 1973a), the frequency of these malformations among sibs of probands was found to be around 4 to $5 \%$, a sevento fifteen-fold increase compared with the population frequencies. Other relationships are not as well documented: though the number of spina bifida cystica survivors who have reproduced is as yet small in follow up studies, the proportion affected among their children may be similar to that of sibs, and risk to children of male patients appears to be at least as high as that of children of female patients (Carter and Evans, 1973b). In two large studies (Carter et al., 1968; Carter and Evans, 1973a), an approximately two-fold increase was found in mothers' sisters' children, but this is also the group of cousins for whom information is likely to be more complete (Carter, 1976). No significant increase of parental consanguinity was found in these studies.

Concordance in twins generally appears to be less than recurrence in sibs. Whether zygosity affects concordance or not is not settled: it does not seem so in the data considered by Nance (1969) or by Leck (1974), but it does seem so in the series assembled from published reports by Rogers and Weatherall (1976). In an Australian survey, where zygosity was assigned from recorded evidence of chorion status, concordance rates were in agreement with the heritability suggested by sib data (Field and Kerr, 1974).

\section{ABORTION STUDIES}

Prenatal mortality due to neural tube malformations is high and is related to severity of affection. Around $90 \%$ of anencephalic cases ascertained among all births, live or stillbirths, are stillborn, and it was therefore likely that the proportion of neural tube malformations detected at birth represented only a fraction of all cases among conceptions. A family study in Glasgow (Richards et al., 1972) suggested that sibs of affected children have an increased risk of being aborted. Nishimura (1970), in Japan, found 10 cases of anencephaly and 11 cases of 'myeloschisis' among 3535 induced abortions (5.8 per 1000). In London, a study of spontaneous abortions led to an estimate of a prevalence of $5 \cdot 3$ per 1000 conceptuses at the beginning of the eighth week of gestation (Creasy and Alberman, 1976), suggesting that 54\% abort spontaneously. Both series were too small to yield reliable estimates by sex. In a study of regional variation in frequency at birth of these malformations, Roberts and Lloyd (1973) found an inverse relation between previous spontaneous abortion rate and the prevalence at birth of neural tube malformations that could not be explained in terms of social class, parity, or maternal age differences. This study, moreover, suggested that the substantial and relatively stable regional differences in prevalence among all births could be controlled by small area differences in mortality of malformed embryos. It follows that the relevance of the various epidemio- 
logical and familial features reported to an understanding of the aetiology of these malformations cannot be properly assessed without consideration of fetal mortality, and the bearing of these considerations on the present analysis will be discussed later.

\section{Segregation analysis}

\section{DATA SUBMITTED TO ANALYSIS}

The data from two large family surveys in South Wales (Carter, et al., 1968) and in Greater London (Carter and Evans, 1973a) were submitted to segregation analysis under the mixed model. Affected individuals were recorded as anencephaly or spina bifida according to the definition given in this paper.

\section{SEGREGATION ANALYSIS UNDER THE MIXED} MODEL

Under the mixed model (Morton and MacLean, 1974), of which a brief description can be found in Lalouel et al. (1977), affection is related to an underlying scale of liability through a threshold. As defined in these surveys, anencephaly and spina bifida are both heterogeneous in terms of severity or time of onset during pregnancy, and whether occurrence of a given clinical form is related to liability cannot be presumed. Hence, affection status is defined as occurrence of any one of these clinical forms. For the same reasons, fetal mortality cannot be accounted for in the model in the absence of more extensive studies of spontaneous abortions. In view of the importance of this fetal loss, our results should be

Table 1 Summary of input data

\begin{tabular}{|c|c|c|c|c|c|}
\hline & & \multicolumn{3}{|c|}{$\begin{array}{l}\text { Prevalence among births (live } \\
\text { and stillbirths) }\end{array}$} & Sex ratio \\
\hline $\begin{array}{l}\text { South Wales } \\
\text { Greater London }\end{array}$ & $\begin{array}{l}\text { A } \\
\text { SB } \\
\text { ASB } \\
\text { A } \\
\text { SB } \\
\text { ASB }\end{array}$ & $\begin{array}{l}0.0017 \\
0.0038 \\
0.0055 \\
0.0008 \\
0.0013 \\
0.0021\end{array}$ & $\begin{array}{l}0.0054 \\
0.0045 \\
0.0099 \\
0.0020 \\
0.0018 \\
0.0038\end{array}$ & $\begin{array}{l}0.0035 \\
0.0041 \\
0.0077 \\
0.0014 \\
0.0015 \\
0.0030\end{array}$ & $\begin{array}{l}0.34 \\
0 \cdot 89 \\
0.59 \\
0.41 \\
0.79 \\
0.58\end{array}$ \\
\hline & \multicolumn{3}{|c|}{ No. of sibships } & \multicolumn{2}{|c|}{ Probability of ascertainment } \\
\hline $\begin{array}{l}\text { South Wales } \\
\text { Greater London }\end{array}$ & & $\begin{array}{l}58 \\
64\end{array}$ & & & \\
\hline
\end{tabular}

A, anencephaly; SB, spina bifida; ASB, A or SB. considered with caution. The sex difference in pre valence of affection is taken into account through $\mathrm{a}^{\text {t }}$ shift of the liability scale, hence defining tw $\vec{f}$ different thresholds.

No reliable estimates of prevalence according to항 maternal age and birth order being available fot these two series, these effects have not been considere in the present study. All matings involve only normas parents, and therefore there is no information ow environment common to sibs $(B=0)$. In segregatio analysis, prevalence of affection for each sex are input parameters; they were taken to be as given b $\vec{w}$ the authors of these surveys. Probabilities of ascers. tainment were estimated in each sample by analysing the distribution of probands among affected in aft sibships, using the computer program SEGRAN (Morton, 1969). The results are given in Table 1. $\infty$

Segregation analysis was carried out with the computer program SHIFT (C. J. MacLean, 1974, unpublished data; Lalouel et al., 1977). No con? vergence could be obtained estimating simulo taneously the parameters of the mixed modet frequency of major gene (q), dominance (d), dis placement $(t)$, and polygenic heritability $(H)$, an 6 inspection of the likelihood did not reveal highet values than obtained when $\mathbf{H}=0$ or when $q=0$.

Maximum likelihood estimation under the multio factorial model (where only $\mathrm{H}$ is estimated ant $\mathrm{q}=0)$ of both sets of data pooled $(-2 \ln \mathrm{L}+\mathrm{C}=$ 650.26) and separated (Table 2) showed significan heterogeneity $\left(\chi^{2}{ }_{1}=6 \cdot 86\right)$, so that analysis was pursued for each set separately. As can be seen i $\overrightarrow{\vec{m}}$ Table 2, estimates under the generalised single locuş model $(\mathrm{H}=0)$ for each sample do not yield a likel误 hood appreciably different from that of the multifactorial model. Hence, rather than asserting the existence of a major gene, we retain the more conservative multifactorial model as a description of the familial aggregation observed. Different thresholds for each sex yield a likelihood ver significantly higher than the likelihood obtaine when sex is not considered (see Table 2).

\section{Recurrence risks for neural tube malformations}

Having retained the multifactorial model with sexspecific thresholds, risks for a child born after a

Table 2 Segregation analysis of neural tube malformations

\begin{tabular}{|c|c|c|c|c|c|c|c|c|}
\hline & \multicolumn{4}{|c|}{ Generalised single locus with sex difference in liability } & \multicolumn{2}{|c|}{$\begin{array}{l}\text { Multifactorial model with } \\
\text { sex difference in liability }\end{array}$} & \multicolumn{2}{|c|}{$\begin{array}{l}\text { Multifactorial model without } \\
\text { sex difference in liability }\end{array}$} \\
\hline & $d$ & $t$ & $q$ & $-2 \ln L+C$ & $H$ & $-2 \ln L+C$ & $\boldsymbol{H}$ & $-2 \ln L+C$ \\
\hline $\begin{array}{l}\text { South Wales } \\
\text { Greater London }\end{array}$ & $\begin{array}{l}1 \cdot 0 \\
1 \cdot 0\end{array}$ & $\begin{array}{l}2 \cdot 2 \pm 0 \cdot 25 \\
2 \cdot 0 \pm 0 \cdot 29\end{array}$ & $\begin{array}{l}0.004 \pm 0.002 \\
0.012 \pm 0.010\end{array}$ & $\begin{array}{r}664 \cdot 4 \\
-20 \cdot 6\end{array}$ & $\begin{array}{l}0.76 \pm 0.08 \\
0.90 \pm 0.08\end{array}$ & $\begin{array}{r}663 \cdot 3 \\
-19 \cdot 9\end{array}$ & $\begin{array}{l}0.74 \pm 0.08 \\
0.90 \pm 0.08\end{array}$ & $\begin{array}{r}720 \cdot 1 \\
24 \cdot 5\end{array}$ \\
\hline
\end{tabular}


affected sib have been calculated with the program RISK (C. J. MacLean, 1974, unpublished data; Lalouel et al., 1977). In each case, the risk is given for an individual of unknown sex, together with, in parentheses, risk for a male and a female, respectively.

For normal parents in South Wales, the risk after having one male affected is $0.058(0.045,0.072)$; after having one female affected it is $0.051(0.039$, 0.064). After two affected sibs, the risk for a third one to be affected varies from 0.09 for a male birth after two affected females to $0 \cdot 16$ for a female birth after two males affected. This makes it necessary to resort to calculation of a specific recurrence risk in any particular counselling situation. Examples for a few particular nuclear families are presented in the Fig.

In the Discussion, it is argued that the estimate of heritability with the Greater London data is likely to be inflated by ethnic heterogeneity, so that pending

No. 259

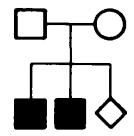

0.135

$(0 \cdot 109,0 \cdot 162)$

No. 580

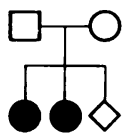

0.116

$(0.093,0.140)$

No. 29

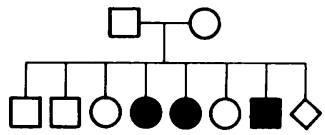

0.144

$(0 \cdot 116,0 \cdot 172)$

No. 340

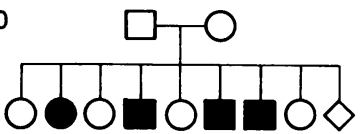

$0 \cdot 197$

$(0 \cdot 162,0 \cdot 232)$

No. 133

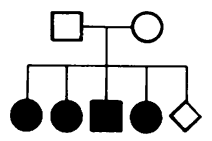

$0 \cdot 247$

$(0 \cdot 208,0 \cdot 287)$

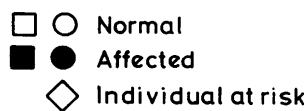

Fig. Specific recurrence risks for certain families in South Wales. For each family, recurrence risk is given for an individual of unknown sex, together with the risks when sex is male or female, respectively. Sources: Carter et al. (1968), as indicated by proband identification number. better knowledge about the causes of regional variation in prevalence, it is suggested that, in any counselling situation where no better estimate is available, the estimate of heritability obtained in South Wales should be used for risk calculation, together with an appropriate estimate of sex-specific prevalence for the reference population to which the consultand belongs.

\section{Discussion}

The multifactorial model with sex-specific thresholds can be used for calculation of recurrence risks in South Wales until better knowledge is acquired on the pathogeny of these malformations, and more information on fetal mortality at various stages of embryonic development is obtained from abortion studies. In Greater London, however, the population is heterogeneous. Carter and Evans (1973a) noted that their family sample showed a striking excess of patients born to parents from India and Pakistan, compared to parents born in the West Indies, in relation to households of immigrant parents in the 1966 sample census. Their tabulation of the proportion of sibs affected by birth of all four grandparents of index patients confirms documented evidence of variability in incidence and familial aggregation in Britain, India, and the West Indies. This may explain the high estimate of heritability in Greater London.

Abortion studies previously referred to, together with a study of regional variation of prevalence at birth of neural tube malformations and previous abortion rates (Roberts and Lloyd, 1973), suggest that variation in fetal mortality may account for a number of the reported epidemiological features. It may be responsible for most of the regional variation observed in the British Isles, and possibly also, together with biases in reporting, an important part of the international variation. In Nishimura's data (1970), anencephaly and spina bifida occur with similar frequencies among early abortions, but prevalence at birth is low in Japan, and spina bifida rare. In Creasy and Alberman's study (1976), males and females were found in equal proportion among fetuses greater than $30 \mathrm{~mm}$ crown-rump, with some differences of anatomical lesions among sexes. However, sex ratio at birth is low in the British Isles, particularly in regions of high prevalence at birth, and the female prevalence of anencephaly seems more labile in space as well as in time (Leck, 1972; Rogers and Morris, 1973). Those data suggest a differential mortality among sexes and possible differences in severity among forms affecting each sex. The existence of a real sex difference in incidence of affection at conception cannot be proved until studies of very 
early abortions are done, as closure of the neural tube occurs around the third week of gestation, and excess of male abortuses before the eighth week of gestation cannot yet be ruled out.

The low concordance rate in twins, together with the observed sex difference in prevalence at birth, and the observed correlation in time and space between dizygotic twinning and prevalence of neural tube malformations, have prompted a number of pathogenic hypotheses invoking cytoplasmic inheritance (Nance, 1969), or some form of fetus-fetus interaction (Rogers, 1969, 1976; Knox, 1970, 1974). However, both the excess of same-sex pairs and the low concordance observed, as in the series assembled by Rogers and Weatherall (1976), could be explained by the high fetal mortality of malformed conceptions, provided that genetic factors play some role, since discordant twins would then have a higher survival rate than concordant twins, and monozygotic twins a higher survival rate than dizygotic twins. Observed rates would then be biased by differential survival rates of twins. It is significant that Carter (1976) considers that 'no adequate data on neural tube malformations are yet available' in relation to twinning. A similar argument was proposed by Lazar (1976) to interpret secular and maternal age variations of dizygotic twinning, and this could in turn explain the temporal and spatial correlations reported between dizygotic twinning and neural tube malformations, either through mortality factors affecting both rates, or as a consequence of variation in demographic characteristics affecting those rates through the similar maternal age effects reported for both.

A number of associations with environmental agents have been reported, such as intake of potatoes affected by blight (Renwick, 1972), of tea (Fedrick, 1973), of water with low mineral content (Lowe et al., 1971), or various other agents (see Leck, 1974, for a review). These associations, if substantiated, would point to the importance of environmental effects, without excluding the possible role of the genetic background.

In view of the data available at present, the multifactorial model of inheritance can be used for calculation of recurrence risks of neural tube malformations. Studies of early abortions are necessary before any improvement on this model can be made by taking into account differential survival rates. Without such studies, pathogenic hypotheses involving twinning remain poorly supported by empirical evidence. Substantial studies of half-sibs are required to separate maternal and fetal liability. Pending these, the multifactorial model should be considered as a provisionally acceptable basis for calculating recurrence risks, but not as a proven hypothesis.

\section{References}

Carter, C. O. (1976). Genetics of common single malformations. British Medical Bulletin, 32, 21-26.

Carter, C. O., David, P. A., and Laurence, K. M. (1968). family study of major central nervous system malfornations in South Wales. Journal of Medical Genetics, 81-106.

Carter, C. O., and Evans, K. A. (1973a). Spina bifida aळ̆d anencephalus in Greater London. Journal of Medical Genetics, 10, 209-234.

Carter, C. O., and Evans, K. A. (1973b). Children of adult survivors with spina bifida cystica. Lancet, 2, 924-926. .

Creasy, M. R., and Alberman, E. D. (1976). Congenifal malformations of the central nervous system in sp 6 taneous abortions. Journal of Medical Genetics, 13, 9-1.

Elwood, J. H. (1976). Anencephaly and spina bifida in $\overline{\mathrm{B}} \mathrm{e}$ British Isles. In Birth Defects: Risks and Consequences, pp. 21-39. Ed. by S. Kelly, E. B. Hook, D. T. Janeri雨, and I. H. Porter. Academic Press, New York.

Elwood, J. H., and Nevin, N. C. (1973). Factors associated with anencephalus and spina bifida in Belfast. Britsh Journal of Preventive and Social Medicine, 27, 73-80.

Elwood, J. M. (1976). Ancephalus and spina bifida in North America. In Birth Defects: Risks and Consequençs, pp. 3-19, Ed. by S. Kelly, E. B. Hook, D. T. Janerich, a d I. H. Porter. Academic Press, New York.

Fedrick, J. (1970). Anencephalus: variation with matermal age, parity, social class and region in England, Scotland and Wales. Annals of Human Genetics, 34, 31-38.

Fedrick, J. (1973). Communication to a meeting of the Britich Association for the Advancement of Science, Canterbuify. Quoted by Leck (1974).

Field, B., and Kerr, C. (1974). Twinning and neural-t震e defects. Lancet, 2, 964-965.

Imaizumi, Y. (1974). Statistical analysis on anencephaidy, spina bifida and congenital hydrocephaly in Japfon. Japanese Journal of Human Genetics, 19, 115-135.

Knox, E. G. (1970). Fetus-fetus interaction. A mozfel aetiology for anencephalus. Developmental Medicine agd Child Neurology, 12, 167-177.

Knox, E. G. (1974). Twins and neural tube defects. Bri蒫h Journal of Preventive and Social Medicine, 28, 73-80.

Lalouel, J. M., Morton, N. E., MacLean, C. J., and Jackson, J. (1977). Recurrence risks in complex inheritance wh special regard to pyloric stenosis. Journal of Medlsal Genetics, 14, 408-414.

Lazar, P. (1976). Effets des avortements spontanés sur Ia fréquence des naissances gémellaires. Comptes Renđus Hebdomadaires des Séances de l'Académie des Scienęes, 282, 243-246.

Leck, I. (1969). Ethnic differences in the incidence of mâlformations following migration. British Journal of Preven and Social Medicine, 23, 166-173.

Leck, I. (1972). The etiology of human malformationg: insights from epidemiology. Teratology, 5, 303-314. o

Leck, I. (1974). Causation of neural tube defects: clues finem epidemiology. British Medical Bulletin, 30, 158-163.

Lowe, C. R., Roberts, C. J., and Lloyd, S. (1971). Malformations of central nervous system and softness of local water supplies. British Medical Journal, 2, 357-361.

Morton, N. E. (1969). Segregation analysis. In Comp \& Applications in Genetics, pp. 129-139. Ed. by N. E. Mort黑n.

Morton, N. E., Chung, C. S., and Mi, M. P. (1967). Genet⿱宀's of Interracial Crosses in Hawaii. Karger, Basel.

Morton, N. E., and MacLean, C. J. (1974). Analysis of fantly resemblance. III. Complex segregation of quantitaIve traits. American Journal of Human Genetics, 26, 489-5. 
Naggan, L. (1971). Anencephaly and spina bifida in Israel. Pediatrics, 47, 577-586.

Naggan, L. (1976). I. Methodology of ascertainment in international comparisons. II. Anencephaly and spina bifida in Israel. In Birth Defects: Risks and Consequences, pp. 41-58. Ed. by S. Kelly, E. B. Hook, D. T. Janerich, and I. H. Porter. Academic Press, New York.

Naggan, L., and MacMahon, B. (1967). Ethnic differences in the prevalence of anencephaly and spina bifida in Boston, Mass. New England Journal of Medicine, 277, 1119-1123.

Nance, W. E. (1969). Anencephaly and spina bifida: a possible example of cytoplasmic inheritance in man. Nature, 224, 373-374.

Neel, J. V. (1958). A study of major congenital defects in Japanese infants. American Journal of Human Genetics, 10, $398-445$.

Nishimura, H. (1970). Incidence of malformations in abortions. In Congenital Malformations, pp. 275-283. Ed. by F. C. Fraser and V. A. McKusick. Excerpta Medica, Amsterdam.

Renwick, J. H. (1972). Hypothesis: anencephaly and spina bifida are usually preventable by avoidance of a specific but unidentified substance present in certain potato tubers. British Journal of Preventive and Social Medicine, 26, 67-88.

Richards, I. D. G., McIntosh, H. T., and Sweenie, S. (1972). A genetic study of anencephaly and spina bifida in Glasgow. Developmental Medicine and Child Neurology, 14, 626-639.

Roberts, C. J., and Lloyd, S. (1973). Area differences in spontaneous abortion rates in South Wales and their relation to neural tube defect incidence. British Medical Journal, 4, 20-22.

Rogers, S. C. (1969). Epidemiology of stillbirths from congenital abnormalities in England and Wales 1961-1966. Developmental Medicine and Child Neurology, 11, 617-629.
Rogers, S. C. (1976). Anencephalus, spina bifida, twins, and teratoma. British Journal of Preventive and Social Medicine, 30, 26-28.

Rogers, S. C., and Morris, M. (1973). Anencephalus: a changing sex ratio. British Journal of Preventive and Social Medicine, 27, 81-84.

Rogers, S. C., and Weatherall, J. A. C. (1976). Anencephalus, Spina Bifida and Hydrocephalus: England and Wales 1964-72. OPCS Studies on Medical and Population Subjects, No. 32. HMSO, London.

Searle, A. G. (1959). The incidence of anencephaly in a polytypic population. Annals of Human Genetics, 23, 279-288.

Smith, C. (1976). Statistical resolution of genetic heterogeneity in familial disease. Annals of Human Genetics, 39, 281-291.

Timson, J. (1969). The sex ratio in spina bifida. Genetica, 40, 427-433.

Timson, J. (1970). The sex ratio in anencephaly. Genetica, 41, 457-465.

Williamson, E. M. (1965). Incidence and family aggregation of major congenital malformation of central nervious system. Journal of Medical Genetics, 2, 161-172.

Wilson, T. S. (1970). Congenital malformations of the central nervous system among Glasgow births 1964-68. Health Bulletin, 28, 32-38.

Yen, S., and MacMahon, B. (1968). Genetics of anencephaly and spina bifida. Lancet, 2, 623-626.

Requests for reprints to Dr J. M. Lalouel, Population Genetics Laboratory, University of Hawaii at Manoa, 1980 East-West Road, Honolulu, Hawaii 96822. 